\title{
Clinicohistopathological correlation of pigmented skin lesions: a hospital based study at BPKIHS
}

\author{
Isha Bohra ${ }^{1}$, Punam Paudyal ${ }^{1}$, Anju Pradhan ${ }^{1}$, Dhan Keshar Khadka ${ }^{2}$ \\ ${ }^{I}$ Department of Pathology, B. P. Koirala Institute of Health Sciences, Dharan, Nepal. \\ ${ }^{2}$ Department of Dermatology and Venerology, B. P. Koirala Institute of Health Sciences, Dharan, Nepal.
}

\author{
Keywords: \\ Melanoma; \\ Melanocytic; \\ Nevi; \\ Nonmelanocytic; \\ Pigmented skin lesions
}

\begin{abstract}
Background: Pigmented skin lesions refers to melanocytic as well as nonmelanocytic lesions. Pigmentation is not just a cosmetic deformity but can also reflect underlying benign pathology as nevi or malignant lesions as melanoma. With this study we intend to evaluate the spectrum of pigmented skin lesions and to correlate the clinical diagnosis with the histological diagnosis.

Materials and Methods: This is a hospital based cross sectional descriptive study where clinicohistopathological evaluation of 46 cases of pigmented skin lesions were analyzed on paraffin embedded tissue sections for a duration of 1 year at the Department of Pathology, B. P. Koirala Institute of Health Sciences.

Results: Out of the 46 cases evaluated there were 32 cases of melanocytic lesions comprising of benign melanocytic nevi $(n=27)$, malignant melanoma $(n=5)$ and 14 cases of nonmelanocytic lesions including basal cell carcinoma and seborrhoeic keratosis ( 5 cases each). Angiokeratoma $(n=1)$, sebaceous hyperplasia $(n=1)$, trichoepitheloma $(n=1)$ and venous haemangioma $(n=1)$. The age range was from $8-83$ years with slight female predominance $(52.2 \%)$ and the most common site involved was head and neck (58.7\%). $76.1 \%$ of the patients belonged to the Terai region. Clinicohistopathological correlation showed positive correlation in 26 cases $(56.5 \%)$ and negative correlation in 20 cases (43.5\%).

Conclusion: Pigmented skin lesions are common presenting problem, while majority are benign a small minority can be malignant. So, clinically pigmented skin lesions should be submitted for pathological examination in order not to miss a small percentage of malignant tumors and to differentiate melanocytic lesions from its nonmelanocytic mimickers.
\end{abstract}

\section{Correspondence:}

Dr. Isha Bohra, MD

Department of Pathology,

BP Koirala Institute of Health Sciences, Dharan, Nepal

ORCID ID: 0000-0001-6662-376Xs

Email-isha.bohra2308@gmail.com

Reveived : May $15^{\text {th }} 2019$; Accepted : August $18^{\text {th }} 2019$

Citation: Bohra I, Paudyal P, Pradhan A, Khadka DK. Pigmented skin lesions Clinicohistopathological Correlation: A hospital based study at BPKIHS. J Pathol Nep 2019;9:19504.DOI: $10.3126 /$ jpn.v9i2.24080

Copyright: This is an open-access article distributed under the terms of the Creative Commons Attribution 4.0 International License, which permits unrestricted use, distribution, and reproduction in any medium, provided the original author and source are credited.

\section{INTRODUCTION}

Pigmented skin lesions (PSLs) include both melanocytic as well as nonmelanocytic lesions. ${ }^{1}$ Disorders of pigmentation can result from migration abnormalities of melanocytes from neural crest to the skin during embryogenesis, impairment of melanosome transfer to keratinocytes and alteration in melanin synthesis. ${ }^{2}$

Melanocytes are pigment-producing cells. The function of melanocytes is the production of melanin, Melanin protects the mitotically active basal epidermal cells from the injurious effects of ultraviolet light, which accounts for individuals with less pigmentation having a much greater 
risk of sunburn and developing cutaneous malignancies like squamous cell carcinoma, basal cell carcinoma, and melanoma. $^{3}$

Pigmentation is not just a cosmetic deformity causing psychosocial upset but can also reflect underlying pathology as nevi and other benign pigmented lesions are important precursor of malignant melanoma. ${ }^{1}$

Melanocytic proliferations are composed of one or more of three related cell types; melanocytes, nevus cells or melanoma cells, each of which may be in epidermis or dermis and occasionally in subcutis. Benign tumors of nevus cells are called melanocytic nevi, while malignant tumors are called malignant melanoma. ${ }^{4}$

Melanoma accounts for about $5 \%$ of all skin cancers but, according to American Cancer Society, causes $77 \%$ of all skin cancer related deaths. As per the 2008, United States cancer statistics showed that melanoma of the skin was the fifth most common cancer in men and the seventh most common cancer in women. As per the $2005-2009$ data, the age adjusted incidence rate for cutaneous melanoma is 21.0 per 100,000 per year. $^{5}$

Many nonmelanocytic skin lesions have pigmented variants that can defy clinical recognition and mimic clinically melanocytic lesions including malignant melanoma, such mimickers include seborrhoeic keratosis, basal cell carcinoma, actinic keratosis, dermatofibrosarcoma protuberans, lichen planus pigmentosus. Histopathological examination helps to confirm/refute the clinical diagnosis and helps in treatment of patients with PSLs. ${ }^{6}$ With this study, we intend to evaluate the spectrum of PSLs and to correlate the clinical diagnosis with the histological diagnosis.

\section{MATERIALS AND METHODS}

A hospital based cross sectional descriptive study spanning over a period of 1 year, from July 2015 to June 2016, was carried out at the Department of Pathology, B. P. Koirala Institute of Health Sciences (BPKIHS). A total of 46 patients of all age groups having PSL clinically and/ or confirmed by histopathology were included in the study. PSLs were analysed considering the histologic type, anatomic location, tumor type, along with age, sex and geographical distribution of the patient. Patient or patient party who fail to give consent or history with inflammatory, infectious, metabolic and endocrine lesions are excluded from the study.

For histopathological examination, Hematoxylin and Eosin stained formalin fixed paraffin embedded tissue sections were examined. Special stains were performed whenever necessary (Masson Fontana and Melanin bleach). All the slides were evaluated by consultant pathologist.

Ethical clearance was obtained from Institutional Review Committee, BPKIHS. (Acd/374/'072/'073) The collected data was entered in Microsoft Office Excel 2007 software. Data analysis was done by using SPSS (Statistical Package for Social Sciences) 11.5 versions. The study considered $95 \%$ confidence interval. Population enumeration was used for sampling technique.

\section{RESULTS}

Histopathological study of 46 cases of PSLs were evaluated where maximum cases encountered was benign melanocytic nevi (27), malignant melanoma, basal cell carcinoma and seborrhoeic keratosis were found in equal frequency ( 5 cases each). Angiokeratoma (1), sebaceous hyperplasia (1), trichoepitheloma (1) and venous haemangioma (1) were the lesions which did not contribute to a significant proportion.

In the study population, the age ranged from $8-83$ years. Benign melanocytic nevi was seen most commonly in the age group $20-40$ years $(n=15,55.60 \%)$. All the cases ( 5 each) of malignant melanoma, pigmented BCC and seborrhoeic keratosis were seen in patient more than 40 years of age. In the current study $52.2 \%$ were female and $47.8 \%$ were male.

Most common site involved was head and neck $(\mathrm{n}=27$, $58.7 \%)$, followed by trunk ( $\mathrm{n}=11,23.9 \%)$, lower limbs $(\mathrm{n}=7$, $15.2 \%)$ and upper limbs $(n=1,2.2 \%)$. All the 5 cases of malignant melanoma were seen in lower limbs. Pigmented basal cell carcinoma (BCC) were seen in head and neck $(n=4,80 \%)$ and only $(n=1,20 \%)$ were seen in lower limb.

According to Geographic distribution majority of the patients $(n=35,76.1 \%)$ belonged to Terai region and remaining $(\mathrm{n}=11,23.9 \%)$ patients from Hilly regions.

\begin{tabular}{|c|c|c|}
\hline \multicolumn{2}{|c|}{ Histopathological Diagnosis } & \multirow{2}{*}{$\begin{array}{c}\text { Number of Cases \% } \\
5(10.9)\end{array}$} \\
\hline \multirow{2}{*}{ Melanocytic } & $\begin{array}{l}\text { Malignant } \\
\text { Melanoma }\end{array}$ & \\
\hline & $\begin{array}{c}\text { Benign Melanocytic } \\
\text { Nevi }\end{array}$ & $27(58.7)$ \\
\hline \multirow{7}{*}{ Non-Melanocytic } & Pigmented BCC & $5(10.9)$ \\
\hline & $\begin{array}{l}\text { Seborrhoeic } \\
\text { Keratosis }\end{array}$ & $5(10.9)$ \\
\hline & Angiokeratoma & $1(2.2)$ \\
\hline & $\begin{array}{l}\text { Sebaceous } \\
\text { Hyperplasia }\end{array}$ & $1(2.2)$ \\
\hline & Trichoepitheloma & $1(2.2)$ \\
\hline & $\begin{array}{c}\text { Venous } \\
\text { Haemangioma }\end{array}$ & $1(2.2)$ \\
\hline & Total & $46(100)$ \\
\hline
\end{tabular}


Table 2: Clinical and histopathological correlation of pigmented skin lesions

\begin{tabular}{|c|c|c|c|}
\hline \multirow{2}{*}{ Clinical Diagnosis } & \multirow{2}{*}{ No. of Case } & \multicolumn{2}{|c|}{ Histopathological Diagnosis } \\
\hline & & Consistent & Inconsistent \\
\hline Malignant Melanoma & $7(15.22 \%)$ & $5(10.87 \%)$ & Pigmented BCC* $(n=2)$ \\
\hline Benign Melanocytic Nevi & $28(60.87 \%)$ & $19(41.30 \%)$ & $\begin{array}{c}\text { Pigmented BCC }(\mathrm{n}=2) \\
\text { Seborrhoeic Keratosis }(\mathrm{n}=3) \\
\text { Angiokeratoma }(\mathrm{n}=1) \\
\text { Sebaceous Hyperplasia }(\mathrm{n}=1) \\
\text { Trichoepitheloma }(\mathrm{n}=1) \\
\text { Venous Haemangioma }(\mathrm{n}=1)\end{array}$ \\
\hline Seborrhoeic Keratosis & $5(10.87 \%)$ & $2(4.35 \%)$ & $\begin{array}{l}\text { Benign Melanocytic Nevi }(\mathrm{n}=2) \\
\text { Pigmented BCC }(\mathrm{n}=1)\end{array}$ \\
\hline Dermatofibroma & $2(4.35 \%)$ & - & Benign Melanocytic Nevi $(\mathrm{n}=2)$ \\
\hline Pilar Cyst & $1(2.17 \%)$ & - & Benign Melanocytic Nevi $(\mathrm{n}=1)$ \\
\hline Neurofibroma & $1(2.17 \%)$ & - & Benign Melanocytic Nevi $(\mathrm{n}=1)$ \\
\hline Papilloma & $2(4.35 \%)$ & - & Benign Melanocytic Nevi $(\mathrm{n}=2)$ \\
\hline Total & $46(100 \%)$ & $26(56.5 \%)$ & $20(43.5 \%)$ \\
\hline
\end{tabular}

*BCC-Basal cell carcinoma

4 cases of malignant melanoma were from Terai region $(80.00 \%)$ whereas only 1 case $(20.00 \%)$ was from Hilly region. All the 5 cases of pigmented $\mathrm{BCC}$ were seen in patients from Terai region.

Among the total cases studied, 36 cases (78.3\%) were benign whereas 10 cases $(21.7 \%)$ were malignant. Among total studied cases, melanocytic lesions accounted for $69.6 \%$ cases whereas non melanocytic lesion comprised of $30.4 \%$ of cases. (Table 1 )

Among all the 27 cases of benign melanocytic nevi, 14 cases were intradermal, 10 cases were compound and there was 1 case each of congenital melanocytic nevi, halo nevus and nevus of Ito.

In this study an analysis of the clinical diagnosis with the histopathological diagnosis revealed a positive correlation in 26 cases $(56.5 \%)$ and negative correlation in 20 cases (43.5\%) (Table 2).

The present study included 5 cases of malignant melanoma. Clarks grading of malignant melanoma revealed grade 4 and 5 tumor in $40 \%$ cases each, while grade 2 was seen in $20 \%$ cases only.

Four cases showed Breslow's depth in stage 1 which predicts good prognosis while 1 case was in stage 2 which predicts bad prognosis. Patient with stage 2 Breslow in the study presented with metastasis to liver. Of the 5 cases of primary melanoma ulcer was reported in 3 cases.

\section{DISCUSSION}

In this study we studied the spectrum of pigmented skin lesions and their mimickers. Histopathologic examination serves as a complementary or a confirmative part of diagnosis.
The median age of patients in current study was found to be 42.5 years with malignant cases seen in older patients as compared to benign. Benign melanocytic nevi was seen most commonly in the age group 20-40 years which is concordant with study performed by Laishram $\mathrm{R}$ et al. ${ }^{7}$ Malignant melanoma and pigmented BCC were seen in patients above 40 years of age which is similar to study by Dafe Forae $G$ et al where majority of the malignant skin tumors occurred between the third to fifth decades and peak age for malignant melanoma was fifth decade. ${ }^{8}$ Konrad $\mathrm{P}$ et al in his study found average age of 51 years for primary cutaneous melanoma. $^{9}$

This study comprised of $47.8 \%$ males and $52.2 \%$ females, showing slight female predominance, which is comparable to study done by Suvernakar et $\mathrm{al}^{1}$, Laishram $\mathrm{R}$ et $\mathrm{al}^{7}$ and Leung K et al. ${ }^{10}$ The higher number of lesions removed from female can be attributed to behavioral difference between male and female patient in seeking medical attention. ${ }^{10}$ Kwok Y et al in their study on melanocytic nevi concluded, that majority of patients were women, which is similar to this study. ${ }^{11}$

There was considerable geographic variation in the incidence of PSLs where $76.1 \%$ patients belonged to Terai region and only $23.9 \%$ patients were from hilly region. This variation can be related to exposure to sunlight and the susceptibility of the population. In a study done by Harrison $\mathrm{S}$ et al on body-site distribution of melanocytic nevi in young Australian children they found that melanocytic nevi are distributed over the body in a way that implicates exposure to sunlight. ${ }^{12}$ Newton-Bishop JA et al and Boniol $\mathrm{M}$ et al in their study also concluded that sun-sensitive phenotypes and reported sunburn were associated with an increased risk of melanoma. ${ }^{13,14}$

The most common site involved in this study was head and neck (58.7\%), followed by trunk $(23.9 \%)$, lower limbs $(15.2 \%)$ and upper limbs $(2.2 \%)$ which is concordant with 
Table 3: Comparison of Clark's grading of malignant melanoma

\begin{tabular}{|c|c|c|c|c|c|}
\hline Clarks Level & $\begin{array}{c}\text { Hussein MR } \\
\text { et } \mathrm{al}^{20} \\
(\mathrm{n}=21)\end{array}$ & $\begin{array}{c}\text { Mukhopadhyay } S \\
\text { et } \mathbf{a l}^{20} \\
(\mathrm{n}=21)\end{array}$ & $\begin{array}{c}\text { Konrad P } \\
\text { et } \text { al }^{9} \\
(n=72)\end{array}$ & $\begin{array}{c}\text { Suvernakar } S \\
\text { et }^{\text {al }^{1}} \\
(\mathrm{n}=5)\end{array}$ & $\begin{array}{l}\text { Present Study } \\
\quad(n=5)\end{array}$ \\
\hline 1 & -- & $18.2 \%$ & $29.2 \%$ & -- & -- \\
\hline 2 & $9.0 \%$ & $18.2 \%$ & $12.3 \%$ & -- & $20.0 \%$ \\
\hline 3 & $14.0 \%$ & $36.2 \%$ & $32.3 \%$ & $40.0 \%$ & -- \\
\hline 4 & $28.6 \%$ & $18.2 \%$ & $26.0 \%$ & $20.0 \%$ & $40.0 \%$ \\
\hline 5 & $47.61 \%$ & $19.0 \%$ & -- & $40.0 \%$ & $40.0 \%$ \\
\hline
\end{tabular}

the studies performed by Suvernakar S et al, Crasta J et al and Laishram R et al. ${ }^{1,6,7}$ In a study performed by Valiukeviciene $\mathrm{S}$ et al, it was concluded that median densities of nevi was highest on the face which is similar to this study. ${ }^{15}$ It was reported from Japan that $86 \%$ of skin melanomas were found in lower limbs and most of these were found in the sole which is comparable to this study where all the cases of malignant melanoma were seen in lower limbs. ${ }^{16}$ All the cases of BCC were seen in head and neck which is similar to study done by Kumar $\mathrm{S}$ et al where head and neck region was involved in $97.2 \%$ of cases. ${ }^{17}$

In this study, maximum cases were hyperpigmented $84.8 \%$, however $15.2 \%$ were skin colored. The skin colored lesions included benign melanocytic nevi $(n=6)$ and pigmented $\mathrm{BCC}(\mathrm{n}=1)$. Hawsawi $\mathrm{K}$ et al reported a case where benign melanocytic nevi presented as solitary firm skin colored nodule, which was later confirmed on histopathology as nevi. ${ }^{18}$ According to literature benign melanocytic nevi can present as localized pigmented or non-pigmented lesions. ${ }^{4}$

In this study, the accuracy of diagnosing benign melanocytic nevi was found to be $63.04 \%$, whereas accuracy in diagnosis of malignant melanoma was $95.65 \%$. In a study done by Brochez L et al, overall there was $70 \%$ agreement on the diagnostic classification of benign melanocytic lesions. Brochez $\mathrm{L}$ et al also evaluated the inter-observer variation of 20 pathologists in the histological diagnosis of a randomly selected set of suspicious PSLs, by comparing their diagnoses to a reference diagnosis. Overall sensitivity for melanoma was $87 \%$, ranging from $55 \%$ to $100 \%$ between the observers. ${ }^{19}$

Increased awareness of melanoma among health professionals and the public has led to an increase in the number of biopsies of PSLs over time. In the case of melanoma, the pathologist evaluates some tumor characteristics which can affect prognosis and patient management, such as the Breslow thickness and the presence or absence of ulceration. ${ }^{19}$

Comparison of Clarks leveling of malignant melanoma of current study was done with those of studies performed by Suvernakar S et al, Konrad P et al, Hussein MR et al and Mukhopadhyay S et al. (Table 3). 1,9,20,21

Of the 7 cases of melanoma diagnosed clinically only 5 were confirmed microscopically. The remaining 2 inconsistent case was of pigmented BCC. There were 5 cases of pigmented basal cell carcinoma diagnosed on histology which had been clinically misdiagnosed as benign melanocytic nevi $(\mathrm{n}=2)$, melanoma $(\mathrm{n}=2)$ and seborrhoeic keratosis $(\mathrm{n}=1)$. Anderson W et al, in their study on 178 cases of malignant melanoma, had described 2 subsets of melanoma which defy clinical diagnosis, one of which is mistaken for basal cell carcinoma and the other with verrucous appearance is mistaken for seborrheic keratosis..$^{22}$ In study done by Izikson L et al on prevalence of melanoma clinically resembling seborrheic keratosis melanoma was identified in 61 cases $(0.66 \%)$ submitted for histological examination with a clinical diagnosis that included seborrheic keratosis. ${ }^{23}$

A total of 32 cases were confirmed to be melanocytic tumors histologically. Non-melanocytic skin lesions commonly diagnosed as melanocytic tumors clinically included seborrhoeic keratosis, pilar cyst, dermatofibroma, papilloma and neurofibroma. Crasta $\mathrm{J}$ et al reported basal cell carcinoma, seborrhoeic keratosis, actinic keratosis and dermatofibrosarcoma protuberans to be the common nonmelanocytic tumors that resemble melanocytic tumors. ${ }^{6}$ In study done by Suvernakar $\mathrm{S}$ et al. the melanocytic group comprised of benign melanocytic nevi, dysplastic nevi and malignant melanoma while seborrhoeic keratosis, pigmented actinic keratosis and pigmented basal cell carcinoma comprised the non-melanocytic lesions. ${ }^{1}$ Leung $\mathrm{K}$ et al reported that non-melanocytic skin lesions commonly diagnosed as melanocytic tumors clinically included seborrheic keratosis, haematoma, skin tag, dermatofibroma, wart, basal cell carcinoma and inflammatory pigmentation.10 Curley RK et al reported an overall sensitivity (diagnostic accuracy) of $50 \%$ in clinically evaluating pigmented lesions. ${ }^{24}$ This emphasizes the importance and utility of histopathology in arriving at a conclusive diagnosis.

\section{CONCLUSIONS}

PSLs are very common presenting problem, while majority are benign, a small minority can be malignant. Histopathological examination of clinically PSLs differentiates between melanocytic and nonmelanocytic lesions and identifies malignant tumours. Since early detection and treatment of lesions are crucial to decrease functional and cosmetic morbidity and costs, 
histopathological examination of PSLs is essential.

\section{Conflict of interest: None}

\section{REFERENCES}

1. Suvernakar SV, Harwani SR, Deshpande SA. Clinicopathological Study of Pigmented Skin Lesions. IOSR-JDMS 2014;13:70-73. Crossref

2. Priyadarshini D, Jeyachandran P. Histopathological and Clinical Correlation of Hyperpigmented Skin Lesions. IJSR. 2014;3:10-12. $\underline{\text { Crossref }}$

3. McKee PH, Brenn T, Lazar A, Calonje E. McKee's Pathology of the Skin. 4th ed. Elsevier Inc.; 2012. 1906pp.

4. Elder DE. Lever's Histopathology of the Skin. 10th ed. Lippincott Williams and Willkins; 2009. 1408pp.

5. Patterson JW. Practical Skin Pathology; A Diagnostic Approach Elsevier Inc.; 2013. 784pp.

6. Crasta J, Rameshkumar K. Pigmented Lesions Of Nonmelanocytic Origin A Pathological Perspective. Indian J Dermatol. 2002;47(2):847. $\underline{\text { Crossref }}$

7. Laishram R, Myrthong B, Laishram S. Pigmented skin lesions:are they all of melanocytic origin? A histopathological prospective. J Pakistan Assoc Dermatologists. 2013;23:284-88. Crossref

8. Forae GD, Olu-Eddo AN. Malignant skin tumors in Benin City, south-south, Nigeria. Oman Med J. 2013;28:311-15. Crossref

9. Konrad P, Fabris MR, Melao S, Blanco LFDO. Histopathological and epidemiological profile of cases of primary cutaneous melanoma diagnosed in Criciuma-SC between 2005 and 2007. An Bras Dermatol. 2011;86:457-61. Crossref

10. Leung K, Chan K. Pattern of pigmented skin tumours seen by private practitioners in Hong Kong. Hong Kong J Dermatology Venereol. 2007;15:113-7. $\underline{\text { Crossref }}$

11. Kwok Y, Giam Y, Tan S, Sim C. A retrospective study of melanocytic naevi at the National Skin Centre. Ann Acad Med Singapore. 2001;30(1):32-7. Crossref

12. Harrison S, Buettner P, MacLennan R. Body-site distribution of melanocytic nevi in young Australian children. Arch Dermatol. 1999;135:47-52. $\underline{\text { Crossref }}$
13. Newton-Bishop JA, Chang Y-M, Elliot F, Chan M, Leake S. Relationship between sun exposure and melanoma risk for tumours in different body sites in a large case-control study in a temperate climate. Eur J Cancer. 2011;47:732-41. Crossref

14. Boniol M, Autier P, Boyle P, Gandini S. Cutaneous melanoma attributable to sunbed use: systematic review and meta-analysis. BMJ. 2012;345(jul24):e4757. Crossref

15. Valiukeviciene S, Gollnick H, Stang A. Body-site distribution of common acquired melanocytic nevi associated with severe sunburns among children in Lithuania. Int J Dermatol. 2007;46:1242-9. Crossref

16. Ohsumi T, Seiji M. Statistical Study on Malignant Melanoma in Japan (1970-1976). Tohoku J. 1977;121:355-64. Crossref

17. Kumar S, Mahajan BB, Kaur S, Yadav A, Singh N, Singh A. A Study of Basal Cell Carcinoma in South Asians for Risk Factor and Clinicopathological Characterization: A Hospital Based Study. J Ski Cancer. 2014. Crossref

18. Hawsawi $\mathrm{K} \mathrm{Al}$, Zahrani B Al, Bamani S, Sharif S Al, Hawsawi W Al. Acquired Melanocytic Nevus: An Unusual Case Presentation. Dermatol Open J. 2016;1:6-8. Crossref

19. Brochez L, Verhaeghe E, Grosshans E, et al. Inter-observer variation in the histopathological diagnosis of clinically suspicious pigmented skin lesions. J Pathol. 2002;196:459-66. Crossref

20. Hussein MR. Melanocytic dysplastic naevi occupy the middle ground between benign melanocytic naevi and cutaneous malignant melanomas: emerging clues. J Clin Pathol. 2005;58:453-56. Crossref

21. Mukhopadhyay S, Ghosh S, Siddharta D MP. A clinicopathological study of malignant melanoma with special reference to atypical presentation. IJPM. 2008;51:485-8. Crossref

22. Anderson W, Silvers D. Melanoma? It Can't Be Melanoma! A Subset of Melanomas That Defies Clinical Recognition. JAMA. 1991;266:3463-5. Crossref

23. Izikson L, Sober A, Mihm MJ, Zembowicz A. Prevalence of Melanoma Clinically Resembling Seborrheic Keratosis. Arch Dermatol. 2002;138:1562-6. Crossref

24. Curley RK, Cook MG, Fallowfield ME, Marsden RA. Accuracy in clinically evaluating pigmented lesions. BMJ. 1989;299:16-8. $\underline{\text { Crossref }}$ 